\title{
ChemComm
}

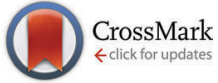

Cite this: Chem. Commun., 2015, 51,12811

Received 5th June 2015

Accepted 6th July 2015

DOI: $10.1039 / c 5 c c 04636 j$

www.rsc.org/chemcomm

\section{Large-scale continuous hydrothermal production and activation of ZIF-8 $\$$}

\author{
A. S. Munn, ${ }^{a}$ P. W. Dunne, ${ }^{a}$ S. V. Y. Tang ${ }^{b}$ and E. H. Lester*a
}

A new method for the large-scale hydrothermal production and activation of ZIF- 8 is presented in this communication. Activated ZIF- 8 has been produced, at lab-scale and pilot-scale, at a rate of $27 \mathrm{~g} \mathrm{~h}^{-1}$ and $810 \mathrm{~g} \mathrm{~h}^{-1}$ respectively with the activated material showing a surface area of $1800 \mathrm{~m}^{2} \mathrm{~g}^{-1}$.

Metal-organic frameworks (MOFs) are porous materials constructed from metal ions and organic ligands. They coordinate to produce channels and cages which are large enough to accommodate various molecules. Zeolitic-imidazolate frameworks (ZIFs) are a subset of MOFs which share some structural characteristics with another group of porous materials known as zeolites. The $\mathbf{M}^{+}-\mathbf{I M}-\mathbf{M}^{+}$angle (where $\mathbf{I M}=$ imidazole) is very similar to the $\mathrm{Si}-\mathrm{O}-\mathrm{Si}$ angle seen in zeolites and it has been shown that this enables them to coordinate to form porous materials with similar coordination geometries. ${ }^{1}$ MOFs, and ZIFs, have been studied extensively in recent years due to the potential for these materials to excel in areas such as $\mathrm{H}_{2}$ storage and $\mathrm{CO}_{2}$ capture; ${ }^{2-4}$ areas which are being driven by government policies and targets. ${ }^{5}$ However, for these materials to be economically and industrially viable then a method for their large scale production and activation needs to be established.

In recent years novel methods for synthesising MOFs have been reported such as microwaves, ${ }^{6-9}$ ultrasound, ${ }^{10}$ and mechanochemical synthesis ${ }^{11}$ which can benefit from reduced synthesis times and easier post-processing of products; however, none of these techniques have been adapted for the continuous production of MOFs. There are only a few reports for the continuous production of MOFs. The first article was published in 2012 by the Lester research group showing the continuous synthesis of HKUST-1 and CPO-27(Ni). ${ }^{12}$ Since then Schoenecker et al. have reported a continuous process for the

\footnotetext{
${ }^{a}$ Department of Chemical and Environmental Engineering, University of Nottingham, NG7 2RD, UK. E-mail: edward.lester@nottingham.ac.uk

${ }^{b}$ Promethean Particles Ltd, 6 Faraday Building, Nottingham, NG7 2QP, UK

$\dagger$ Electronic supplementary information (ESI) available: Further XRD analysis and the results of BET and TGA. See DOI: 10.1039/c5cc04636j
}

synthesis of UiO- $66^{13}$ using their patented reactor which uses batch technology with an integrated flow system to allow for the removal of products and introduction of reagents in situ. The Serre research group described a scalable aerosol system, which uses two liquid reagent streams injected into a flow of hot air, for the synthesis of HKUST-1, ZIF-8 and $\mathrm{Fe}_{3}(\mathrm{BTC})_{2} \cdot{ }^{14} \mathrm{~A}$ similar spray-drying technique was also demonstrated by Carné-Sánchez. ${ }^{15}$ A microfluidic system, established by Faustini et al. ${ }^{16}$ was shown to be a versatile technique for the production of various MOFs including HKUST-1 and UiO-66. And most recently, Rubio-Martinez et al. ${ }^{17}$ reported the continuous synthesis of HKUST-1, UiO-66 and NOTT-400 using a reactor with a T-piece mixer which is followed by a heating unit, where the whole system is held under a pressure of $\sim 7$ bar. A similar T-piece reactor with post-heating was used to continuously produce a cerium-terephthalate MOF at 100 bar. $^{18}$

Where reported, the space-time yields for the different MOFs and techniques described above have been tabulated (Table 1). As a comparison, the MOFs produced by $\mathrm{BASF}^{19-21}$ using an electrochemical process which are sold via Sigma Aldrich under the trademark Basolite ${ }^{\circledR}$ have also been included.

ZIF-8 has been shown to be thermally stable up to a temperature of $450{ }^{\circ} \mathrm{C}$ and also to be chemically stable with respect to boiling water, aqueous sodium hydroxide solutions and benzene. ${ }^{1}$ Venna et al. $^{22}$ also reported that ZIF-8 shows selectivity towards $\mathrm{CO}_{2}$ over $\mathrm{CH}_{4}$ which makes this MOF a good candidate to be scaled-up for industrial processes such as carbon capture and storage (CCS). Many groups have reported the hydrothermal synthesis ${ }^{23-26}$ and continuous synthesis of ZIF- $8,{ }^{14}$ but to the best of our knowledge, none have reported the continuous hydrothermal synthesis of ZIF-8. Using the same reactor technology used to synthesise HKUST-1 and CPO-27 in 2012, ${ }^{12}$ the continuous production of ZIF-8 in a purely hydrothermal system has been achieved. This lab-scale process is capable of producing over $200 \mathrm{~g}$ per day of activated ZIF-8. Using the internal volume of our rig, $55 \mathrm{~mL}$, the spacetime yield for this method is calculated to be $3875 \mathrm{~kg} \mathrm{~m}^{-3}$ per day (full details can be found in the ESI $\dagger$ ), which is an increase 
Table 1 Space time yield (STY) values for MOFs produced using various continuous synthesis techniques

\begin{tabular}{|c|c|c|c|c|}
\hline & MOF & $\begin{array}{l}\text { Reaction } \\
\text { time (min) }\end{array}$ & $\begin{array}{l}\text { Production } \\
\text { rate }\left(\mathrm{g} \mathrm{h}^{-1}\right)\end{array}$ & $\begin{array}{l}\text { STY } \\
\left(\mathrm{kg} \mathrm{m}^{-3} \mathrm{~d}^{-1}\right)\end{array}$ \\
\hline $\begin{array}{l}\text { Preheated counter } \\
\text { current reactor }^{12}\end{array}$ & $\begin{array}{l}\text { ZIF-8 } \\
\text { HKUST-1 } \\
\text { CPO-27 }\end{array}$ & $\begin{array}{l}1 \\
1 \\
1\end{array}$ & $\begin{array}{l}27 \\
30 \\
10\end{array}$ & $\begin{array}{l}3875^{b} \\
4399^{a} \\
1501^{a}\end{array}$ \\
\hline $\begin{array}{l}\text { T-piece reactor with } \\
\text { post heating }{ }^{17}\end{array}$ & $\begin{array}{l}\text { HKUST-1 } \\
\text { UiO-66 } \\
\text { NOTT-400 }\end{array}$ & $\begin{array}{l}1.2 \\
10 \\
15\end{array}$ & $\begin{array}{l}61.2 \\
1.68 \\
2.78\end{array}$ & $\begin{array}{l}4533 \\
672 \\
741\end{array}$ \\
\hline Aerosol heating ${ }^{14}$ & $\begin{array}{l}\text { ZIF-8 } \\
\text { HKUST-1 } \\
\mathrm{Fe}_{3}(\mathrm{BTC})_{2}\end{array}$ & & $\begin{array}{l}1.02 \\
1.93 \\
1.39\end{array}$ & $\begin{array}{l}69.4^{b} \\
494^{b} \\
64^{b}\end{array}$ \\
\hline Microfluidics ${ }^{16}$ & HKUST-1 & 12 & 0.004 & 5.8 \\
\hline $\begin{array}{l}\text { Electrochemical } \\
\text { process }^{21}\end{array}$ & $\begin{array}{l}\text { ZIF-8 } \\
\text { HKUST-1 } \\
\text { MIL-53(Al) } \\
\mathrm{Fe}_{3}(\mathrm{BTC})_{2}\end{array}$ & & & $\begin{array}{l}100 \\
225 \\
160 \\
20\end{array}$ \\
\hline
\end{tabular}

${ }^{a}$ STY calculated using mass of un-activated product. ${ }^{b}$ STY calculated using mass of activated product.

on the values which have been reported previously (Table 1). This reactor technology has already been scaled to 30 times the flow capacity which would enable the production of $\sim 6 \mathrm{~kg}$ per day. Characterisation of the products synthesised using this technology shows that the materials have similar properties as batch-produced materials, making this a viable industrial method for producing ZIF-8. Fig. 1 shows a schematic of the counter-current reactor design which was used for the synthesis of ZIF-8. The setup uses a concentric pipe-in-pipe arrangement which allows rapid mixing of the preheated downstream, delivered through the inner pipe, with the room temperature upstream. ${ }^{27}$ This arrangement allows for instant mixing of the reactants and short residence times as the resultant particle suspension exits the top of the reactor where it is rapidly cooled using a cooling jacket. The pressure in the system can be

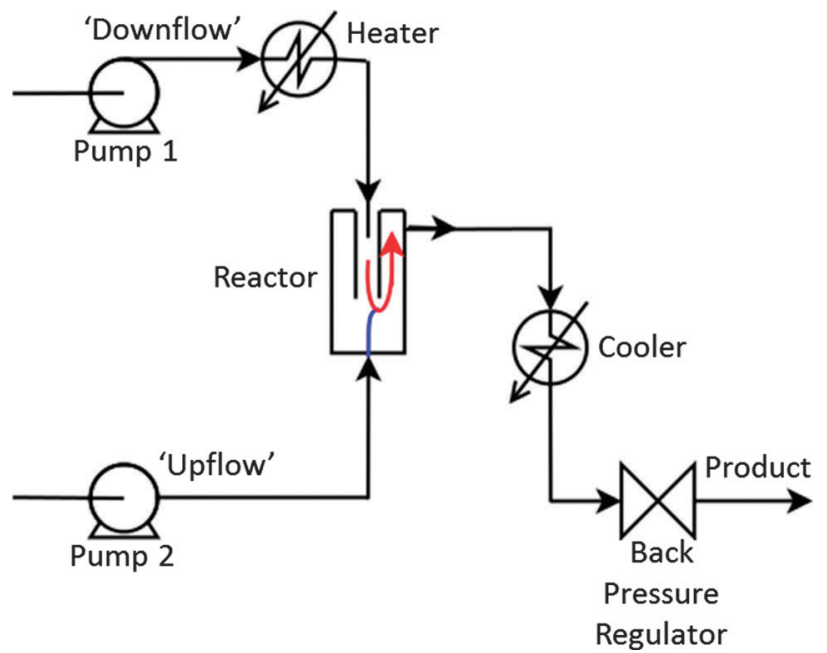

Fig. 1 Schematic of continuous reactor used for the production of ZIF-8. maintained at 240 bar using a back-pressure regulator. For these hydrothermal experiments the organic acid and base were dissolved in the preheated downstream and the metal salt was dissolved in the upstream to prevent any pre-mixing at room temperature which results in a less crystalline product and more impurities.

Three of the published methods for synthesising ZIF-8 in batch were adapted for use in the continuous flow method, they are, in addition to zinc acetate and 2-methylimidazole, the use of (1) triethylamine $\left(\mathrm{N}(\mathrm{Et})_{3}\right)^{25}$ (2) ammonium hydroxide $\left(\mathrm{NH}_{4} \mathrm{OH}\right)^{26}$ and (3) an excess of ligand. ${ }^{23}$ All products synthesised without the use of a base were produced in very low quantities therefore the method was not explored further due to the much higher costs of production. The materials synthesised using triethylamine all grew with a rhombic dodecahedral particle morphology. Control over particle size was obtained by varying the concentration of the metal salt solution whilst maintaining the ratio of reagents, 1:4:6 (zinc acetate: 2-methylimidazole: triethylamine) (Fig. 2). Increasing the synthesis temperature only had the effect of introducing zinc oxide impurities. All products synthesised using triethylamine were unstable during the activation process or gave very low surface areas, thought to be due to the triethylamine being trapped in the pores of the material. Therefore this method of production will not be discussed further.

The use of ammonium hydroxide results in cubic particles, this is in agreement with the batch experiments performed by He et $a l^{26}{ }^{26}$ Powder X-ray diffraction patterns show that ZIF-8 can be produced at room temperature and up to $400{ }^{\circ} \mathrm{C}$ using this continuous flow method; $\ddagger$ at $400{ }^{\circ} \mathrm{C}$ a small amount of $\mathrm{ZnO}$ impurities are present (ESI $\dagger)$. The effect of temperature on the product is a reduction in the average particle size, a change in the particle morphology (Fig. 3) and a small reduction in the BET surface area, assumed to be due to the $\mathrm{ZnO}$ impurities (Fig. 5). All products synthesised using ammonium hydroxide were successfully activated using a simple ethanol reflux method.

ZIF-8 has also been produced on the larger pilot-scale reactor, which uses the same counter-current technology but

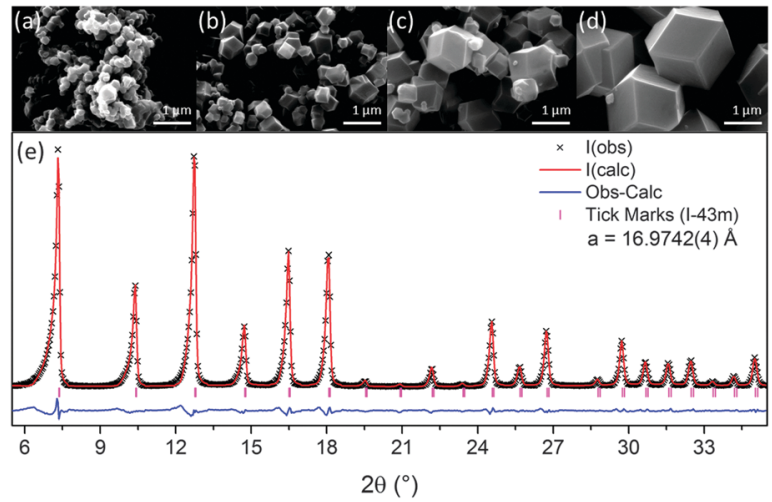

Fig. 2 SEM data of ZIF- 8 prepared using $\mathrm{N}(\mathrm{Et})_{3}$ and synthesised at $100{ }^{\circ} \mathrm{C}$ and a $\mathrm{Zn}^{2+}$ concentration of (a) $0.24 \mathrm{M}$, (b) $0.12 \mathrm{M}$, (c) $0.03 \mathrm{M}$ and (d) $0.015 \mathrm{M}$. (e) Le Bail profile fit $(1 \overline{4} 3 \mathrm{~m})$ to XRD data of ZIF-8 prepared at $100{ }^{\circ} \mathrm{C}$ and $0.06 \mathrm{M}\left(\mathrm{Zn}^{2+}\right)$. 


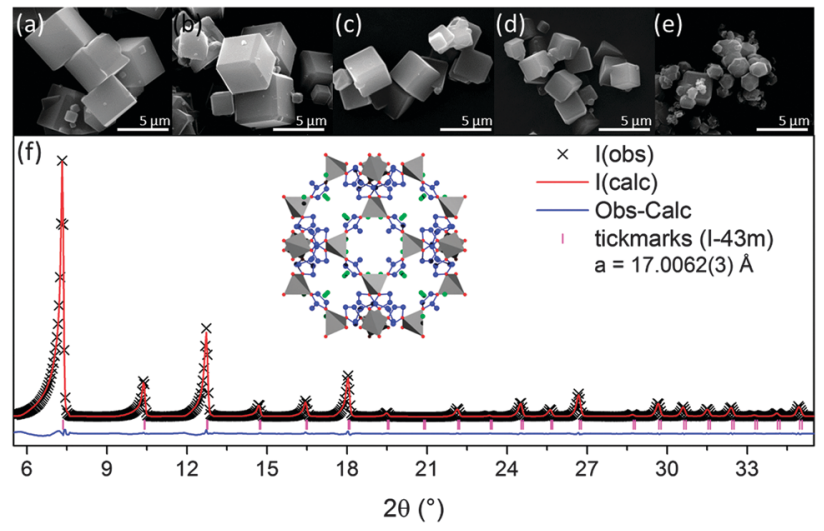

Fig. 3 SEM data of ZIF-8 prepared using $\mathrm{NH}_{4} \mathrm{OH}$ and synthesised at a $\mathrm{Zn}^{2+}$ concentration of $0.06 \mathrm{M}$ and (a) room temperature, (b) $100{ }^{\circ} \mathrm{C}$, (c) $200{ }^{\circ} \mathrm{C}$, (d) $300{ }^{\circ} \mathrm{C}$ and (e) $400{ }^{\circ} \mathrm{C}$. (f) Le Bail profile fit $(/ \overline{4} 3 \mathrm{~m})$ to XRD data of $\mathrm{ZIF}-8$ prepared at $100{ }^{\circ} \mathrm{C}$ and $0.015 \mathrm{M}\left(\mathrm{Zn}^{2+}\right)$

operates at 30 times the flow-rates of the lab-scale reactor giving a total flow-rate of $900 \mathrm{~mL} \mathrm{~min}{ }^{-1}$ compared with $30 \mathrm{~mL} \mathrm{~min}^{-1}$. The pilot-scale sample was synthesised at $100{ }^{\circ} \mathrm{C}$; XRD shows no evidence of crystalline impurities (ESI $\dagger$ ) and the BET surface area is consistent with the equivalent lab-scale sample (Fig. 5). However, the particle morphology was affected. The materials produced on the lab-scale reactor were consistently cubic, with the exception of those produced at $400{ }^{\circ} \mathrm{C}$ which formed truncated rhombic dodecahedra. This morphology was also seen for the particles produced at $100{ }^{\circ} \mathrm{C}$ on the pilot-scale reactor. At $400{ }^{\circ} \mathrm{C}$ the decrease in the density of the fluid causes a decrease in the residence time through the reactor, which has the effect of reducing the size of the particles. For the pilot-scale sample it is believed that the change in size and morphology was also caused by a reduction in the residence time relative to the lab-scale reactor. Various factors affect residence time within flow systems such as temperature, pressure and pipe geometry therefore it is suggested that under these experimental conditions (where autogenous pressure was used) the residence time in the pilot-scale reactor is not directly proportional to the lab-scale reactor. These results indicate that the growth of the ZIF-8 particles occurs via truncated rhombic dodecahedra with growth preferentially occurring on the $\{100\}$ face resulting in cubic particles (Fig. 4).

It should be noted that the initial synthesis of the MOF itself is only the first challenge when seeking to increase the industrial viability of these materials; the second challenge is in the

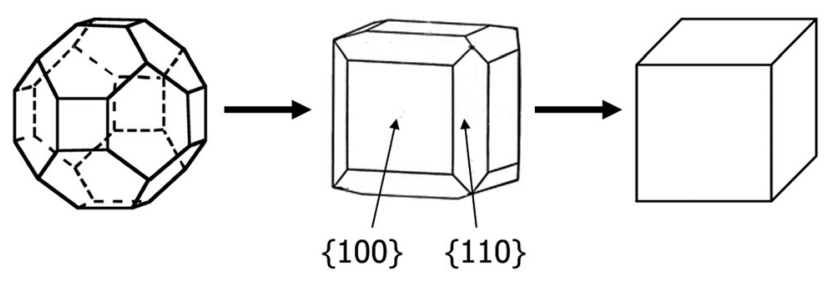

Fig. 4 Growth of truncated rhombic dodecahedron particles to form cubic particles.

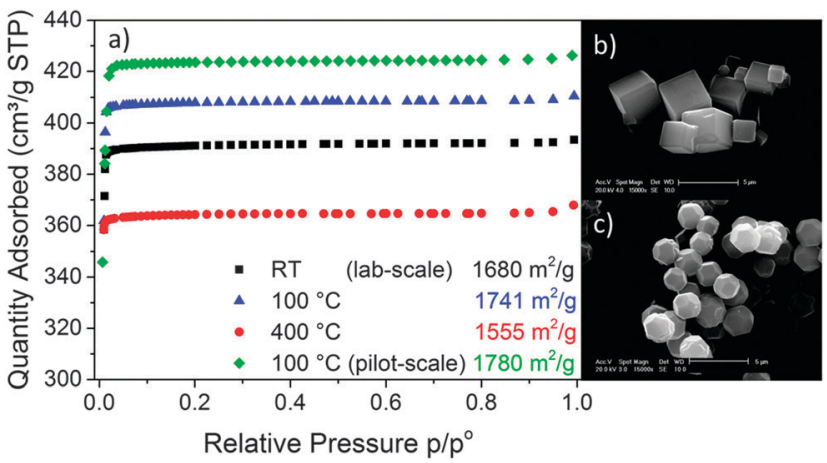

Fig. 5 (a) Nitrogen adsorption isotherms recorded for samples synthesised at RT, 100 , and $400{ }^{\circ} \mathrm{C}$ using the lab-scale reactor and at $100{ }^{\circ} \mathrm{C}$ using the pilot-scale reactor. SEM pictures of ZIF-8 produced at $100{ }^{\circ} \mathrm{C}$ using (b) the lab-scale reactor and (c) the pilot-scale reactor are also shown.

successful activation of the framework which is essential before the porosity of the material can be exploited. Various methods are employed for activating MOFs, the more common methods include, conventional heating under vacuum and solventexchange. ${ }^{28}$ Two relatively new methods have been shown to be promising techniques for activating a wider range of frameworks, including some that cannot be activated by conventional methods, ${ }^{29}$ these are the use of supercritical $\mathrm{CO}_{2},{ }^{28,30,31}$ and benzene freeze-drying. ${ }^{32}$ However, all of these techniques are performed in batch which would hinder the high-volume production of application-ready materials.

This works demonstrates a simple method for the one-step continuous synthesis and activation of ZIF- 8 by a straightforward solvent exchange method. The as-synthesised suspension of ZIF-8 in water was taken immediately after exiting the rig and diluted with ethanol to a ratio of either $1: 1,1: 2$ or $1: 3$ (as-synthesised suspension: ethanol). This mixture was then pumped through a coil of tubing at ambient pressure where the coil was (1) held at room temperature, (2) heated to $50{ }^{\circ} \mathrm{C}$ in a water bath, (3) sonicated in a water bath at room temperature or (4) sonicated in a water bath at $50{ }^{\circ} \mathrm{C}$. All samples were centrifuged to collect and dried at $70{ }^{\circ} \mathrm{C}$ in air at ambient pressure, no further postsynthetic treatments were performed. The residence time within the coil was approximately 5 minutes. PXRD shows that some methods resulted in a small amount of ZnO (ESI $\dagger$ ) but all showed

Table 2 Surface areas for ZIF-8 samples activated using the coil reactor. All samples were synthesised as a single product using the following conditions: $\mathrm{Zn}^{2+} 0.06 \mathrm{M}$, ratio 1:2:16 (zinc acetate :2-methylimidazole : ammonium hydroxide), $100{ }^{\circ} \mathrm{C}$. The activation conditions vary as per the table

\begin{tabular}{llll}
\hline & \multicolumn{3}{l}{$\begin{array}{l}\text { Single point surface area } \\
\left(\mathrm{m}^{2} \mathrm{~g}^{-1}\right) \text { recorded at } 0.1 \mathrm{p} / \mathrm{p}^{0}\end{array}$} \\
\cline { 2 - 4 } Conditions/dilution & $1: 1$ & $1: 2$ & $1: 3$ \\
\hline Room temperature & 1700 & 1651 & 1631 \\
Water bath 50 ${ }^{\circ} \mathrm{C}$ & 1634 & $1503^{a}$ & $1602^{a}$ \\
Sonicated $(\mathrm{RT})$ & $1572^{a}$ & $1772^{a}$ & 1571 \\
Sonicated $\left(50{ }^{\circ} \mathrm{C}\right)$ & 1627 & 1622 & $1276^{a}$
\end{tabular}

${ }^{a}$ Indicates the presence of a small amount of $\mathrm{ZnO}$ in activated product (ESI). 


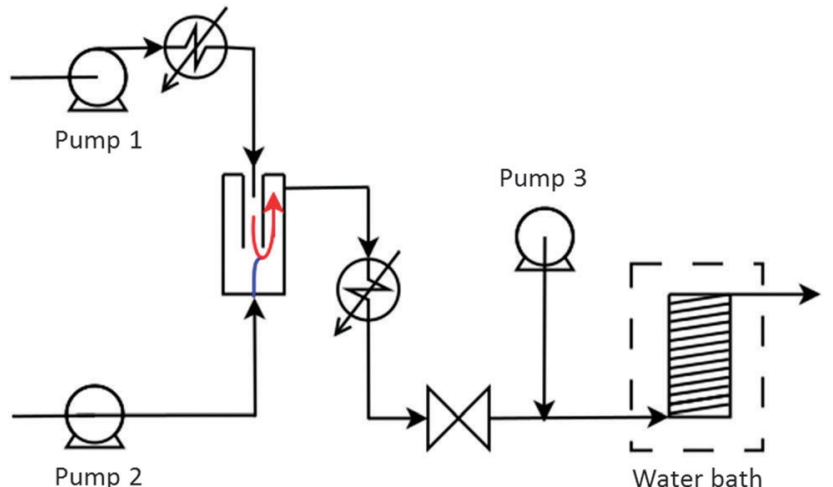

Fig. 6 Schematic showing the combination of the synthesis and activation rigs where the ethanol used for activation is flown in at pump 3, after the back pressure regulator.

high surface areas (Table 2). Room temperature and a ratio of $1: 1$ were shown to be sufficient to activate the material successfully as highlighted in the table. The use of ethanol, instead of diluting with more water, was necessary as the as-synthesised ZIF-8 forms a very stable suspension in pure water which cannot be centrifuged efficiently. The successful activation of all the ZIF-8 samples and the fact that the activation rig can be easily connected to the synthesis rig (as indicated in Fig. 6) shows that this method is a viable technique for industrial production which could dramatically cut post-processing times.

This report demonstrates the large-scale production of ZIF-8 in a continuous hydrothermal system. More importantly this work shows a route to the one-step continuous synthesis and activation of these materials. The ability to activate the material in situ will reduce time and cost of full-scale production. This method represents a viable industrial method for the production of activated ZIF-8.

This work is funded through the European Union's Seventh Framework Programme (FP7/2007-2013), grant agreement no. FP7-NMP4-LA-2012-280983, the SHYMAN project.

\section{Notes and references}

\$Continuous synthesis of ZIF-8 on the lab-scale: downflow$\left(20 \mathrm{~mL} \mathrm{m^{-1 }}\right) 1 \mathrm{~L}$ aqueous solution of 2 -methylimidazole $(4.93 \mathrm{~g}$, $0.06 \mathrm{M}$, Aldrich) and ammonium hydroxide (26.55 mL, 0.48 M, Fisher).

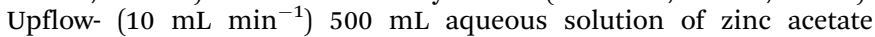
dihydrate (6.59 g, $0.06 \mathrm{M}$, Aldrich).

1 K. S. Park, Z. Ni, A. P. Côté, J. Y. Choi, R. Huang, F. J. Uribe-Romo, H. K. Chae, M. O'Keeffe and O. M. Yaghi, Proc. Natl. Acad. Sci. U. S. A., 2006, 103, 10186-10191.

2 L. J. Murray, M. Dinca and J. R. Long, Chem. Soc. Rev., 2009, 38, 1294-1314.
3 J. Liu, P. K. Thallapally, B. P. McGrail, D. R. Brown and J. Liu, Chem. Soc. Rev., 2012, 41, 2308-2322.

4 J. Pérez-Pellitero, H. Amrouche, F. R. Siperstein, G. Pirngruber, C. Nieto-Draghi, G. Chaplais, A. Simon-Masseron, D. Bazer-Bachi, D. Peralta and N. Bats, Chem. - Eur. J., 2010, 16, 1560-1571.

5 DECC, UK Renewable Energy Roadmap, 2011.

6 Y.-K. Seo, G. Hundal, I. T. Jang, Y. K. Hwang, C.-H. Jun and J.-S. Chang, Microporous Mesoporous Mater., 2009, 119, 331-337.

7 S.-H. Jhung, J.-H. Lee and J.-S. Chang, Bull. Korean Chem. Soc., 2005, 26, 880-881.

8 J. Klinowski, F. A. Almeida Paz, P. Silva and J. Rocha, Dalton Trans., 2011, 40, 321-330.

9 Z. Ni and R. I. Masel, J. Am. Chem. Soc., 2006, 128, 12394-12395.

10 W.-J. Son, J. Kim, J. Kim and W.-S. Ahn, Chem. Commun., 2008, 6336-6338.

11 M. Klimakow, P. Klobes, A. F. Thünemann, K. Rademann and F. Emmerling, Chem. Mater., 2010, 22, 5216-5221.

12 M. Gimeno-Fabra, A. S. Munn, L. A. Stevens, T. C. Drage, D. M. Grant, R. J. Kashtiban, J. Sloan, E. Lester and R. I. Walton, Chem. Commun., 2012, 48, 10642-10644.

13 P. M. Schoenecker, G. A. Belancik, B. E. Grabicka and K. S. Walton, AlChE J., 2013, 59, 1255-1262.

14 A. Garcia Marquez, P. Horcajada, D. Grosso, G. Ferey, C. Serre, C. Sanchez and C. Boissiere, Chem. Commun., 2013, 49, 3848-3850.

15 A. Carné-Sánchez, I. Imaz, M. Cano-Sarabia and D. Maspoch, Nat. Chem., 2013, 5, 203-211.

16 M. Faustini, J. Kim, G.-Y. Jeong, J. Y. Kim, H. R. Moon, W.-S. Ahn and D.-P. Kim, J. Am. Chem. Soc., 2013, 135, 14619-14626.

17 M. Rubio-Martinez, M. P. Batten, A. Polyzos, K.-C. Carey, J. I. Mardel, K.-S. Lim and M. R. Hill, Sci. Rep., 2014, 4, 5443.

18 L. D'Arras, C. Sassoye, L. Rozes, C. Sanchez, J. Marrot, S. Marre and C. Aymonier, New J. Chem., 2014, 38, 1477-1483.

19 U. Mueller, H. Puetter, M. Hesse, M. Schubert, H. Wessel, J. Huff and M. Guzmann, International Pat., WO/2005/049484 A1, 2005.

20 M. Schubert, U. Mueller, M. Hesse and U. Diehlmann, International Pat., WO/2007/090809 A1, 2007.

21 A. U. Czaja, N. Trukhan and U. Muller, Chem. Soc. Rev., 2009, 38, 1284-1293.

22 S. R. Venna and M. A. Carreon, J. Am. Chem. Soc., 2010, 132, 76-78.

23 Y. Pan, Y. Liu, G. Zeng, L. Zhao and Z. Lai, Chem. Commun., 2011, 47, 2071-2073.

24 K. Kida, M. Okita, K. Fujita, S. Tanaka and Y. Miyake, CrystEngComm, 2013, 15, 1794-1801.

25 A. F. Gross, E. Sherman and J. J. Vajo, Dalton Trans., 2012, 41, $5458-5460$.

26 M. He, J. Yao, Q. Liu, K. Wang, F. Chen and H. Wang, Microporous Mesoporous Mater., 2014, 184, 55-60.

27 E. H. Lester and B. J. Azzopardi, International Pat., WO/2005/077505, 2005.

28 J. E. Mondloch, O. Karagiaridi, O. K. Farha and J. T. Hupp, CrystEngComm, 2013, 15, 9258-9264.

29 H. Furukawa, N. Ko, Y. B. Go, N. Aratani, S. B. Choi, E. Choi, A. Ö. Yazaydin, R. Q. Snurr, M. O'Keeffe, J. Kim and O. M. Yaghi, Science, 2010, 329, 424-428.

30 O. K. Farha, I. Eryazici, N. C. Jeong, B. G. Hauser, C. E. Wilmer, A. A. Sarjeant, R. Q. Snurr, S. T. Nguyen, A. Ö. Yazaydın and J. T. Hupp, J. Am. Chem. Soc., 2012, 134, 15016-15021.

31 Y.-S. Bae, D. Dubbeldam, A. Nelson, K. S. Walton, J. T. Hupp and R. Q. Snurr, Chem. Mater., 2009, 21, 4768-4777.

32 L. Ma, A. Jin, Z. Xie and W. Lin, Angew. Chem., Int. Ed., 2009, 48, 9905-9908. 